\title{
Induction of the acid inducible lipF promoter is reversibly inhibited in $\mathrm{pH}$ ranges of $\mathrm{pH} 4.2-4.0$
}

\author{
Rachelle Torres ${ }^{2}$, Donna Dorriz ${ }^{1}$ and Beatrice Saviola ${ }^{1 *}$ (D)
}

\begin{abstract}
Objective: In the human body pathogenic mycobacteria encounter low pH within the phagosomes of macrophages where they reside after being internalized by the host cell. Low pH within macrophages has been shown to induce expression of a variety of genes within these bacteria. It had been previously observed that the Mycobacterium tuberculosis lipF promoter is transcriptionally upregulated between pHs 4.5-6.4 in Mycobacterium smegmatis, with an upper pH limit of 6.4 capable of promoter induction. To better understand the parameters of acid induced gene expression, we sought to determine the lower pH limit capable of lipF promoter induction.

Results: As we had already determined an upper pH limit, we determine here that there is a lower limit of pH's capable of upregulating the lipF promoter, with $\mathrm{pH}$ below 4.3 not positively upregulating the promoter. At non-inducing $\mathrm{pH} 4.2$ the bacterial cells remain viable in the absence of acid induced lipF promoter upregulation and subsequent exposure to acid pH 5.0 results in lipF promoter upregulation. There appears to be a lower limit of pH capable of upregulating lipF promoter expression and this limit is not due to cell death.
\end{abstract}

Keywords: Acidic stress, lipF, Lipase, Mycobacterium tuberculosis

\section{Introduction}

Tuberculosis continues to be an important health problem in the world with a large fraction of the population infected with Mycobacterium tuberculosis, the causative agent of tuberculosis [1]. Like other mycobacteria, $M$. tuberculosis senses and responds to acidic stress $[2,3]$. Previously we had identified a 477 base pair region upstream of the $M$. tuberculosis lipF gene that was transcriptionally upregulated by acidic stress [4]. A homologue of the lipF gene was previously identified in Mycobacterium smegmatis and is implicated in acidic stress [5]. Importantly, a transposon insertion mutant in between the lipF gene and its 59 base pair acid inducible minimal promoter resulted in a mutant $M$. tuberculosis that does not produce LipF and was more attenuated in

\footnotetext{
*Correspondence: bsaviola@westernu.edu

${ }^{1}$ Basic Medical Sciences, College of Osteopathic Medicine, Western

University of Health Sciences, 309 E. Second St., Pomona, CA 91766, USA
}

Full list of author information is available at the end of the article mice and macrophages indicating the gene product aids M. tuberculosis in resisting acidic stress [6]. The product of the lipF gene is predicted to be a lipase or esterase, and proven to act as a lipase [7].

The lipF promoter region was reduced to a 59 base pair minimal region which retained the ability to be upregulated by acidic stress [8]. Within this region we also identified a -10 six base pair region proposed to bind RNA polymerase and analyzed it by mutational analysis [9]. As the original $\mathrm{pH}$ at which the lipF promoter had been identified was $\mathrm{pH} 4.5$, the highest $\mathrm{pH}$ to also induce the promoter was sought and determined to be $\mathrm{pH} 6.4$ [10]. This is a $\mathrm{pH}$ that may be encountered within the phagosomes of macrophages where $M$. tuberculosis resides within the human body. During infection M. tuberculosis is phagocytosed by macrophages and the $\mathrm{pH}$ can drop to as low as 4.5 within phagosomes but can then increase to a range from $\mathrm{pH} 6.0-6.5$ [11-14]. Thus the previously described range of lipF promoter activity between $\mathrm{pH} 4.5$ and 6.4 is well within this spectrum allowing the 
bacterium to be more resistant to acidic stress. In this present study we determine a lower $\mathrm{pH}$ limit of lipF promoter upregulation, which may be important to understand acid sensing mechanisms of mycobacteria.

\section{Main text}

\section{Results}

The minimal acid inducible lipF promoter of M. smegmatis is composed of 59 base pairs upstream of the $M$. tuberculosis lipF gene and this was fused to $g f p$ to create

Table 1 Shuttle plasmids used in the experiments that can be amplified in $E$. coli and transformed into $M$. smegmatis

\begin{tabular}{ll}
\hline PFPV27 & Reporter plasmid with promoterless gfp \\
pBEN & Reporter plasmid with constitutive heat \\
& shock promoter driving constitutive \\
& expression of $g f p$ \\
Reporter plasmid with lipF minimal acid \\
inducible promoter driving expres- \\
sion of $g f p$
\end{tabular}

the plasmid $p M P R$ (Table 1) [8]. This promoter is upregulated by acidic stress within $M$. tuberculosis as well as within $M$. smegmatis, consequently an acid sensing apparatus is similar in these species [4]. As we had previously identified the highest $\mathrm{pH}$ capable of inducing the lipF minimal acid inducible promoter to be $\mathrm{pH}$ 6.4, here we test the lowest possible $\mathrm{pH}$ that can induce the lipF promoter fused to $g f p(p M P R)$. We found that all $\mathrm{pHs}$ tested except for $\mathrm{pH} 4.0,4.1$, and 4.2 could induce the lipF promoter with maximal induction being at $\mathrm{pH} 4.5$ (Fig. 1). This maximum induction coincides with the original $\mathrm{pH}$ used to identify the lipF promoter's acid induction [4, 10]. M. smegmatis containing $p F P V 27$ with a promoterless $g f p$ (Table 1) had little green fluorescent protein (GFP) production. Negative values for M. smegmatis containing $p M P R$ indicate the cells produce less GFP than the bacteria containing promoterless $p F P V 27$. M. smegmatis containing the $p B E N$ plasmid which produces GFP constitutively from a heat shock promoter (Table 1 ) had substantial GFP production as indicated (Fig. 1). As we expected that $\mathrm{pH} 4.2$ would be lethal to mycobacteria and

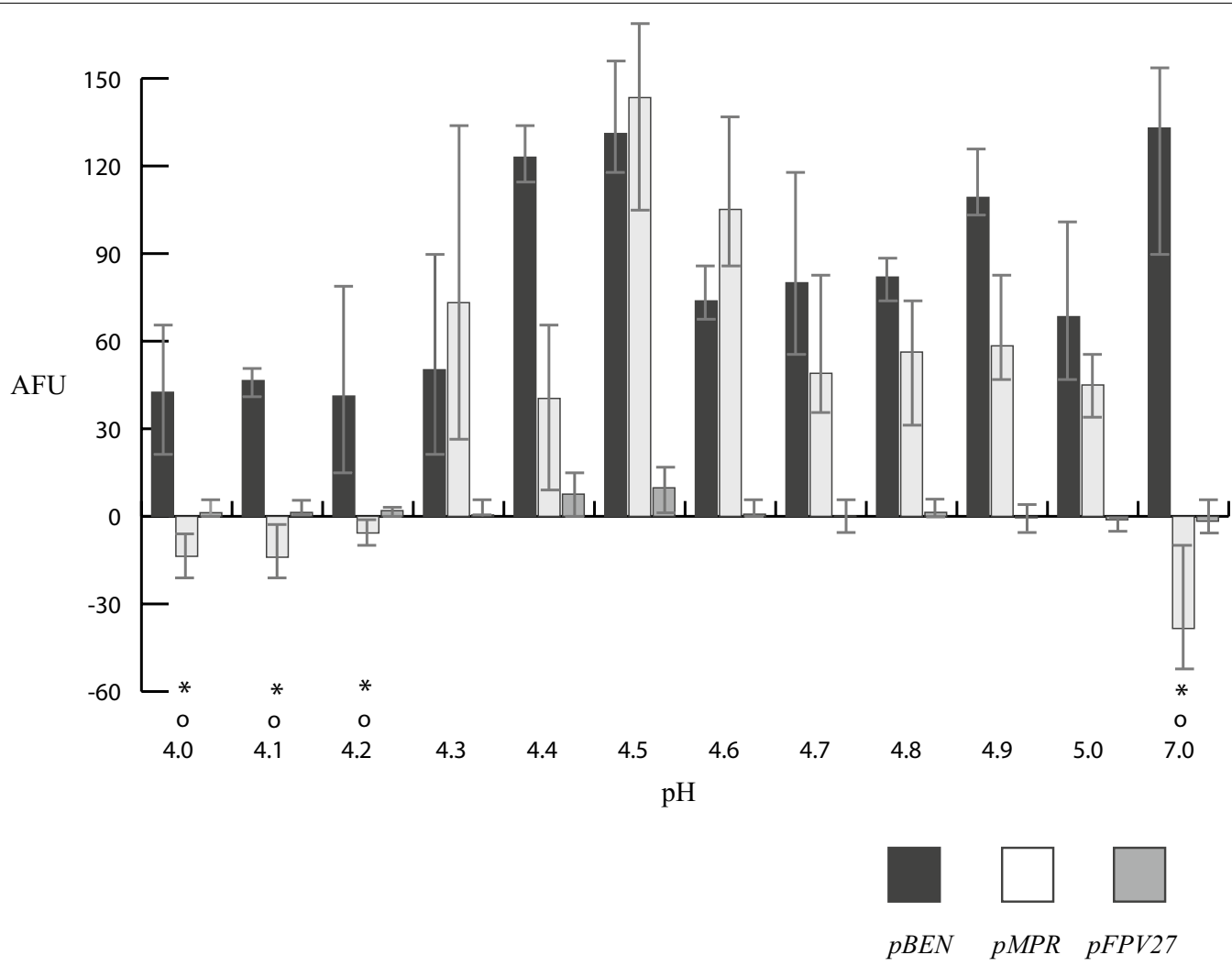

Fig. 1 M. smegmatis containing $P B E N$, $p M P R$, or $p F P V 27$ were grown to mid-logarithmic phase in $\mathrm{pH} 7.0$ media and the $\mathrm{pH}$ was then shifted to $\mathrm{pH}$ 4.0 through 7.0 for a $3 \mathrm{~h}$ exposure. Fluorescence and $\mathrm{OD}_{600}$ were measured. AFU is adjusted fluorescence units and calculated by fluorescence units/optical density units at $600 \mathrm{~nm}$. The data are presented as the mean \pm the standard deviation. ${ }^{*} P<0.03$, significantly different from pH 4.5; ${ }^{\circ} P<0.04$, significantly different from $\mathrm{pH}$ 4.3. There was no statistical difference of cells bearing $p M P R$ at $\mathrm{pH} 4.4,4.5,4.6,4.7,4.8,4.9$, and 5.0 compared to $\mathrm{pH}$ 4.3. Statistical difference was defined as a $P<0.05$. The sample size was 3 and represents biological replicates 
would explain a lack of lipF induction, we tested mycobacterial killing at this $\mathrm{pH}$, and at the same time assayed lipF induction. As before, acid induction of the lipF promoter occurred at $\mathrm{pH} 5.0$ and not at $\mathrm{pH} 4.2$ or $\mathrm{pH} 7.0$ (Fig. 2a). In addition no acid induced bacterial killing occurred at pHs 4.2, 5.0, or 7.0 with $3 \mathrm{~h}$ of exposure, consequently cell death does not explain the lack of induction (Fig. 2b). Exposure to $24 \mathrm{~h}$ of acid media at $\mathrm{pH} 4.5$ resulted in $75 \%$ reduction in viability compared to exposure to $\mathrm{pH} 7.0$ media (Fig. 2b). To further investigate we repeated induction at $\mathrm{pH} 4.2$ for $3 \mathrm{~h}$, centrifuged the bacterial cells, washed them, and resuspended them in $\mathrm{pH}$ 5.0 for another $3 \mathrm{~h}$ and observed positive $l i p F$ induction (Fig. 2a). The lack of induction of the lipF promoter is reversible, as removal of $\mathrm{pH} 4.2$, and exposure to $\mathrm{pH} 5.0$ resulted in lipF promoter induction. Fluorescence photography was performed on $M$. smegmatis at $\mathrm{pH} 4.2,4.3$, 5.0, $7.03 \mathrm{~h}$, or 4.2 exposed for $3 \mathrm{~h}$, centrifuged, washed, and induced at $\mathrm{pH}$ 5.0. M. smegmatis with an $m p r-g f p$ fusion fluoresces brightly after exposure to $\mathrm{pH} 5.0$ and 4.3, but no fluorescence after exposure to $\mathrm{pH} 7.0$ or $\mathrm{pH}$ 4.2 (Fig. 2c). Strikingly fluorescence was also observed after bacterial exposure to $\mathrm{pH} 4.2$ for $3 \mathrm{~h}$, washing, and exposure to $\mathrm{pH} 5.0$ for an additional $3 \mathrm{~h}$ (Fig. 2c). This fluorescence was observed at the end of the $3 \mathrm{~h}$ incubation at $\mathrm{pH}$ 5.0.

\section{Discussion}

In this study we show a lower limit where acidity no longer induces the lipF promoter in $M$. smegmatis. In vivo, $M$. tuberculosis is taken up by macrophages into phagosomes during the infectious process. When macrophages are induced with Interferon gamma (INF- $\gamma$ ), $\mathrm{pH}$ inside the phagosomes decreases to 4.5 and rebounds to $\mathrm{pH} 6.0$ or above $(11,12,13$, and 14). The lipF promoter would be active during these in vivo conditions. In this study we determined the acidic $\mathrm{pH}$ at which lipF fails to be upregulated is $\mathrm{pH} 4.2$ and this $\mathrm{pH}$ is not reported to be present within phagosomes of macrophages that contain viable $M$. tuberculosis bacilli. The lipF promoter may have evolved to detect $\mathrm{pHs}$ actually present within phagosomes.

The transcription factor PhoP has been shown to bind within the lipF promoter but it is unclear if it responds to external acid stress [15]. PhoP is part of a two component system which employs a membrane bound sensor kinase to sense external stimuli and in response phosphorylates PhoP, though acid stress is not known to be involved in PhoP phosphorylation [15]. Sigma factor binding site analysis revealed that the lipF promoter likely uses a principle sigma factor and a deletion strain of the sig $F$ gene encoding a stress response sigma factor revealed that it is likely not involved in lipF promoter regulation as the promoter is upregulated in this strain $[4,9]$. It remains unclear the exact nature of the acid sensing mechanism and the exact transcription factors involved in lipF promoter upregulation.

Bacterial killing or toxicity is unlikely to be the origin of the lack of ability to upregulate the lipF promoter at $\mathrm{pH} 4.2$ as bacteria were measured to not lose viability in $3 \mathrm{~h}$ acid exposure time frame. In the lipF promoter upregulation system a protein factor present on the mycobacterial cell surface may be responsible for sensing $\mathrm{pH}$ with an optimum function between $\mathrm{pH} 6.4$ and 4.3. At $\mathrm{pH} 4.2$ this factor may be reversibly in an inactive configuration to signal to the lipF promoter within the cell. Upon washing away $\mathrm{pH} 4.2$, and resuspending in $\mathrm{pH} 5.0$ the new environment is capable of converting

\footnotetext{
(See figure on next page.)

Fig. 2 a To test if induction at $\mathrm{pH} 4.2$ is reversible, M. smegmatis containing $p B E N, p M P R$, or pFPV27 were grown to mid-logarithmic phase at pH 7.0, then exposed to $\mathrm{pH} 4.2,5.0$, or 7.0 for $3 \mathrm{~h}$. An additional culture had been previously grown at pH 7.0 to mid-logarithmic phase, shifted to $\mathrm{pH} 4.2$ for $3 \mathrm{~h}$, and then shifted to $\mathrm{pH} 5.0$ for an addition $3 \mathrm{~h}$. AFUs were determined as previously described. The data are presented as the mean \pm the standard deviation. ${ }^{*} P<0.04$, significantly different from $\mathrm{pH} 4.23 \mathrm{~h}$ of exposure. The sample size was 3 and represents biological replicates. b To determined viability of mycobacteria exposed to acidity, the M. smegmatis containing $P M P R$ were exposed to $\mathrm{pH} 7.0,5.0$, or 4.2, diluted to 1:10 and plated onto $7 \mathrm{H} 10$ plates. Bacterial colony forming units (CFU)/ml of the undiluted sample were quantitated from the bacterial plates and were normalized by dividing by the $\mathrm{OD}_{600}$ of the bacterial undiluted samples. Exposure to $3 \mathrm{~h}$ of acidity did not reduce mycobacterial viability in any of the conditions tested including $3 \mathrm{~h}$ of exposure to $\mathrm{pH}$ 4.2. As a control M. smegmatis was grown to mid-logarithmic phase and then exposed to $\mathrm{pH} 4.5$ or 7.0 for $24 \mathrm{~h}$. The bacteria were then diluted and plated onto agar plates and the CFU/ml normalized for $\mathrm{OD}_{600}$ as before. As expected exposure to $24 \mathrm{~h}$ at pH 4.5 resulted in a $75 \%$ reduction of viability of the mycobacteria whereas exposure to $\mathrm{pH} 7.0$ did not. The data are presented as the mean \pm the standard deviation. ${ }^{*} P<0.05$, significantly different from $\mathrm{pH} 4.524 \mathrm{~h}$ exposure; ${ }^{\#} P<0.03$, significantly different from $\mathrm{pH} 4.524$ h exposure; ${ }^{+} P<0.02$, significantly different from $\mathrm{pH} 4.524$ h exposure; ${ }^{\circ} \mathrm{P}<0.02$, significantly different from $\mathrm{pH} 7.024 \mathrm{~h}$ exposure. There was no statistical difference for $\mathrm{pH} 4.2$ or $5.03 \mathrm{~h}$ of exposure compared to $\mathrm{pH} 7.03 \mathrm{~h}$ of exposure. There was also no statistical difference between $\mathrm{pH} 4.2,5.0$, or $7.03 \mathrm{~h}$ of exposure compared to $\mathrm{pH} 7.024 \mathrm{~h}$ of exposure. Statistical difference was defined as a $P<0.05$, the sample size was 3 and represents biological replicates. c M. smegmatis containing pMPR was grown to mid-logarithmic phase and exposed to $\mathrm{pH}$ 4.2, 4.3, 5.0, or 7.0 for $3 \mathrm{~h}$, or $4.23 \mathrm{~h}$ and then $5.03 \mathrm{~h}$. Individual M. smegmatis bacilli were visualized via differential interference contrast microscopy (DICM) and fluorescence microscopy at $\times 40$ magnification. This experiment was repeated three times with similar results. Approximately 7 images were sampled for each condition
} 

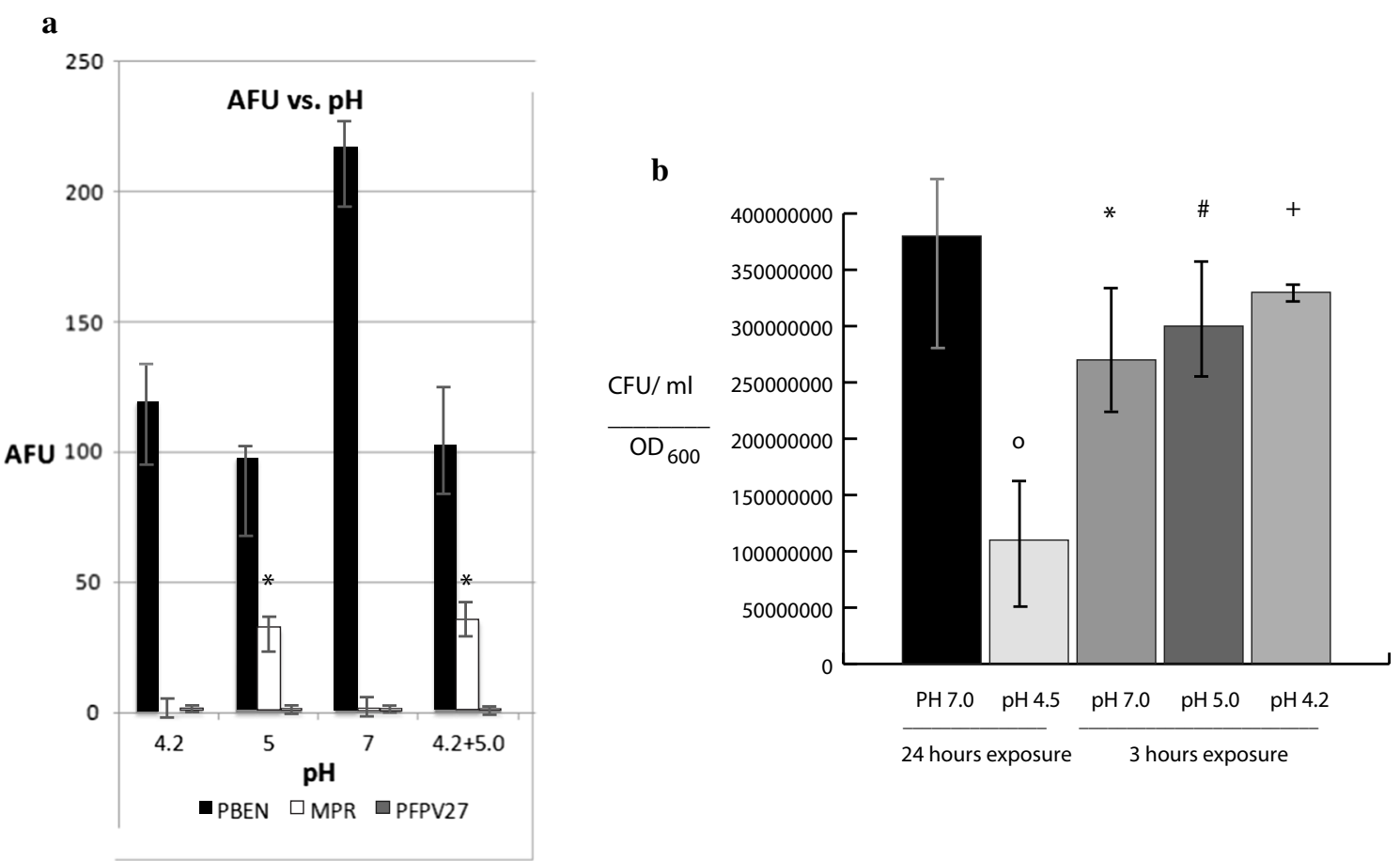

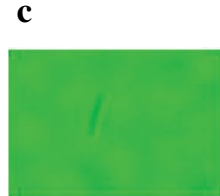

$\mathrm{pH} 4.2$ Brightfield

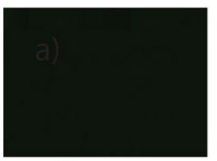

$\mathrm{pH} 4.2$ Fluorescence

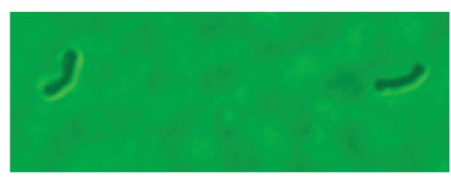

pH 5.0 Brightfield

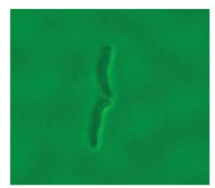

pH 7.0 Brightfield

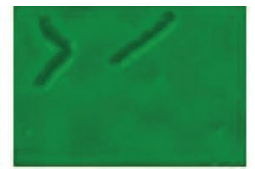

pH 4.3 Brightfield

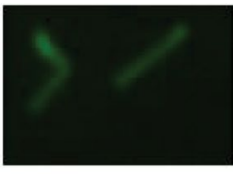

pH 4.3 Fluorescence

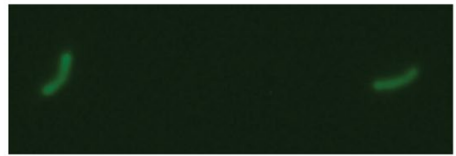

pH 5.0 Fluorescence

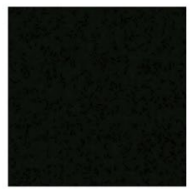

$\mathrm{pH} 7.0$ Fluorescence

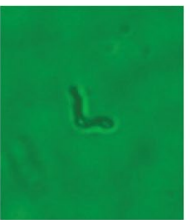

pH 4.2 then 5.0 Brightfield pH 4.2 then 5.0 Fluorescence the conformation to an activating form. In vivo $\mathrm{pH}$ 4.2 is likely never experienced within phagosomes and the factor evolved to be optimally active at acidic $\mathrm{pHs}$ encountered. With manipulation of the intraphagosomal $\mathrm{pH}$ to be slightly lower than normal $(\mathrm{pH} 4.5)$ to 4.2 or lower, genes normally thought to be active during exposure to an acidic phagosome may not be upregulated and decrease $M$. tuberculosis adaptability and increase bacterial cell death.

\section{Conclusions}

Here we show the lower $\mathrm{pH}$ limit for lipF promoter induction is $\mathrm{pH}$ 4.3. Likely the failure to upregulate the acid induced lipF promoter from $\mathrm{pH}$ 4.2-4.0 results from 
dysregulation of the acid sensing/promoter induction machinery that is not related to mycobacterial cell death. This machinery and process may be manipulated in the future using pharmacotherapy in $M$. tuberculosis infected individuals to lower intraphagosomal $\mathrm{pH}$ below the $\mathrm{pH}$ 4.3 limit of acid induction.

\section{Methods}

\section{Strains and media}

Escherichia coli strain DH5 $\alpha$ (ATCC 67878) was used in all experiments to generate and amplify plasmid constructs for further use. E. coli was grown in Luria-Bertani broth and on Luria-Bertani agar petri plates (Fisher Scientific, BP1427-500 and DF0445-17-4). M. smegmatis $\mathrm{Mc}^{2} 155$ (ATCC 700084) was grown at $37{ }^{\circ} \mathrm{C}$ in Middlebrook 7H9 broth (Becton-Dickinson, DF0713-17-9) supplemented with 10\% ADC (bovine serum albumin-Fisher Scientific BP1600-100, dextrose-EMD DX0145-1, and NaCl-EMD SX0420-1), 0.025\% Tween 80 (polyoxyethylenesorbitan monooleate-Fisher Scientific T164-500), and 2\% glycerol (Hoefer GR124-1) in rolling liquid media culture, and in Middlebrook 7H10 agar (Becton-Dickinson, DF0627-17-4) with 10\% ADC for solid surface growth. E. coli was transformed with $50 \mathrm{ng}$ of $p F P V 27$, $p M P R$, and $p B e n$, (Table 1), containing promoterless $g f p$ [16-18], the 59 base pair minimal acid inducible lipF promoter fused to $g f p$ [8], and the heat shock promoter fused to $g f p$ respectively [19]. $25 \mu \mathrm{g} / \mathrm{ml}$ kanamycin (Fisher Scientific AAJ6066803) was utilized for selecting resistant plasmids. Plasmids were isolated using Wizard minipreps (Promega, PR-A1330). 50 ng of purified plasmids were transformed via electroporation into $M$. smegmatis and selection occurred on 7H10 agar with $10 \%$ ADC and $25 \mu \mathrm{g} / \mathrm{ml}$ kanamycin.

\section{Acid promoter induction}

To create acidic media, 2\% HCL (EMD Millipore, MHX06074) was added to $20 \mathrm{ml}$ of 7H9/ADC broth dropwise to reach the desired $\mathrm{pH}$ between 5.0 and 4.0. M. smegmatis containing plasmids were grown in $\mathrm{pH} 7.0$ Middlebrook 7H9 broth to an optical density at $600 \mathrm{~nm}$ $\left(\mathrm{OD}_{600}\right)$ on a Genesys10uv spectrophotometer (Thermofisher 840-208100) of 0.5 (logarithmic phase), the cells were centrifuged for $2 \mathrm{~min}$ at 12,000 rotations per minute (RPM) and $24{ }^{\circ} \mathrm{C}$ in a microcentrifuge (BioRad Model 16K-1660602EDU), supernatant removed, and cells resuspended in 7H9 culture media (Becton-Dickinson) at pHs 5.0-4.0, or neutral pH 7.0, and grown for an additional $3 \mathrm{~h} .3 \mathrm{~h}$ was chosen as this is the approximate generation time of the mycobacteria. All promoter inductions were performed at $37{ }^{\circ} \mathrm{C}$, and all $\mathrm{pH}$ points were tested in triplicate. To terminate inductions, all samples were vortexed with $4 \mathrm{~mm}$ glass beads (Fisher,
50-872-931) to eliminate clumping and were diluted to the same optical density at $600 \mathrm{~nm}$ in $7 \mathrm{H} 9$ broth. Fluorescence of the samples was measured on a TD-700 Turner designs fluorometer (7000-998-Turner Designs) with a $486 \mathrm{~nm}$ (nanometer) excitation filter and a 510-700 nm emission filter. Adjusted fluorescence units were determined to be fluorescence units/optical density units at $600 \mathrm{~nm}$. All measurements in the figures are mean of the values and the error bars are the standard deviation. To further investigate non-inducing $\mathrm{pH} 4.2, \mathrm{M}$. smegmatis was grown in $7 \mathrm{H} 9 \mathrm{pH} 7.0$ until reaching $\mathrm{OD}_{600}$ of 0.5 , exposed to $7 \mathrm{H} 9$ media at $\mathrm{pH} 4.2$ for $3 \mathrm{~h}$, centrifuged, washed, and then resuspended in $\mathrm{pH} 5.0$ for another $3 \mathrm{~h}$, and measured on a TD-700 Turner designs fluorometer as previously described. $\mathrm{pH}$ points were tested in triplicate.

\section{Microscopy}

Bacteria were visualized via differential interference microscopy, and also fluorescence microscopy using a Nikon Eclipse E600. The same field of slide was captured by differential interference contrast microscopy and by fluorescence at $40 \times$ magnification to record identical $M$. smegmatis cells.

\section{Determination of cell viability}

Mycobacterium smegmatis was grown to mid-logarithmic phase, exposed to $\mathrm{pH} 7.0,5.0$ or 4.2 for $3 \mathrm{~h}$, or to $\mathrm{pH} 7.0$ or 4.5 for $24 \mathrm{~h}$. Cells were vortexed with $4 \mathrm{~mm}$ glass beads (Fisher) and the optical density at $600 \mathrm{~nm}$ was determined. To plate the bacteria, the samples were diluted $1: 10^{5}$, and $1: 10^{6}$ and $100 \mu$ of samples were plated onto $7 \mathrm{H} 10$ plates. M. smegmatis was incubated at $37{ }^{\circ} \mathrm{C}$ for 3 days and the number of colonies was counted. The number of bacterial colony forming units (cfus)/ml for an $\mathrm{OD}_{600}$ of 1 was determined. All $\mathrm{pH}$ points were tested in triplicate and the data was described as the mean of the values and the error bars are the standard deviations.

\section{Statistical analysis}

Three biological replicates were performed for each condition and data are represented as the mean \pm standard deviation. An unpaired t test was used to compare means and statistical significance was defined as $P<0.05$.

\section{Limitations}

This data was obtained from M. smegmatis cultures in vitro and may need to be repeated in M. tuberculosis. Only pHs to $\mathrm{pH} 4.0$ were tested and sample pHs below this limit could be investigated in the future. 


\section{Abbreviations}

AFU: adjusted fluorescence units; CFU: colony forming units; E. coli: Escherichia coli; GFP: green fluorescent protein; INF- $\gamma$ : interferon gamma; M. smegmatis: Mycobacterium smegmatis; M. tuberculosis: Mycobacterium tuberculosis; nm: nanometer; $\mathrm{OD}_{600}$ : optical density at $600 \mathrm{~nm}$; RPM: rotations per minute.

\section{Authors' contributions}

RT and DD carried out the acid induction experiments of the lipF minimal promoter and measured gfp expression. RT and BS assayed the survival of $M$. smegmatis at various acidities. RT and BS documented M. smegmatis fluorescence with microscopy. BS developed the experimental design of the work. BS and RT wrote the manuscript, and BS edited the manuscript. All authors read and approved the final manuscript.

\section{Author details}

1 Basic Medical Sciences, College of Osteopathic Medicine, Western University of Health Sciences, 309 E. Second St., Pomona, CA 91766, USA. ${ }^{2}$ Mercy Medical Center Merced Hospital, 333 Mercy Avenue, Merced, CA 95340, USA.

\section{Acknowledgements}

Kind thank you to Dr. Jeffrey Felton for providing editorial suggestions.

\section{Competing interests}

The authors declare that they have no competing interests.

\section{Availability of data and materials}

All data generated or analyzed during this study are included in this published article.

\section{Consent to publish}

Not applicable.

\section{Ethics approval and consent to participate} Not applicable.

\section{Funding}

This work was funded by a Potts Memorial Foundation grant.

\section{Publisher's Note}

Springer Nature remains neutral with regard to jurisdictional claims in published maps and institutional affiliations.

Received: 26 December 2017 Accepted: 20 April 2018

Published online: 08 May 2018

\section{References}

1. World Health Organization, Global Tuberculosis Control 2014; 2014. http://apps.who.int/medicinedocs/documents/s23360en/s23360en.pdf.

2. O'Brien LM, Gordon SV, Roberts IS, Andrew PW. Response of Mycobacterium smegmatis to acid stress. FEMS Microbiol Lett. 1996;9:11-7.
3. Schnappinger D, Ehrt S, Voskuil MI, Liu Y, Mangn JA, Monahan IM, Dolganov G, Efron B, Butcher PD, Nathan C, Schoolnik GK. Transcriptional adaptation of Mycobacterrium tuberculosis within macrophages: insights into the phagosomal environment. J Exper Med. 2003;198:693-704.

4. Saviola B, Woolwine S, Bishai WR. Isolation of acid-inducible genes of Mycobacterium tuberculosis with the use of recombinase-based in vivo expression technology. Infect Immun. 2003;71:1379-88.

5. Tran SL, Rao M, Simmers C, Gebhard S, Olsson K, Cook GM. Mutants of Mycobacterium smegmatis unable to grow at acidic $\mathrm{pH}$ in the presence of the protonophore carbonyl cyanide mchlorophenylhydrozone. Microbiology. 2005;151:665-72.

6. Camacho LR, Ensergueix D, Perez E, Gicquel B, Guilhot C. Identification of a virulence gene cluster of Mycobacterium tuberculosis by signaturetagged transposon mutagenesis. Mol Microbiol. 1999;34:257-67.

7. Zhang $\mathrm{Y}$, Wang $\mathrm{H}$. Expression and characterization of the carboxyl esterase Rv3487c from Mycobacterium tuberculosis. Prot Exp Purific. 2005;42:59-66.

8. Richter L, Tai W, Felton J, et al. Determination of the minimal acid-inducible promoter region of the lipF gene from Mycobacterium tuberculosis. Gene. 2007;395:22-8. https://doi.org/10.1016/j.gene.2006.12.037.

9. Gonzales M, Saviola B. Mutational analysis of the -10 region from the Mycobacterium tuberculosis lipF promoter. Mol Biol Rep. 2009;36:1225-9.

10. Richter L, Saviola B. The lipF promoter of Mycobacterium tuberculosis is upregulated by acidic $\mathrm{pH}$ but not by other stress conditions. Microbiol Res. 2009;164:228-32.

11. Clemens DL, Horwitz MA. Characterization of the Mycobacterium tuberculosis phagosome and evidence that phagosomal maturation is inhibited. J Exp Med. 1995;181:257-70.

12. Deretic V, Fratti RA. Mycobacterium tuberculosis phagosome. Mol Microbiol. 1999;31:1603-9.

13. MacMicking JD, Taylor GA, Mckinney JD. Immune control of tuberculosis by INF- $\gamma$-Inducible LRG-47. Science. 2003;302:654-9.

14. Rohde K, Yates RM, Purdy GE, Russell DG. Mycobacterium tuberculosis and the environment within the phagosome. Immunol Rev. 2007;219:37-54.

15. Cimino M, Thomas C, Namouchi A, Dubrac S, Gicquel B, Gopaul DN. Identification of DNA binding motifs of the Mycobacterium tuberculosis PhoP/PhoR two-component signal transduction system. PLOS ONE. 2012;7(8):e42876.

16. Barker LP, Brooks DM, Small PL. The identification of Mycobacterium marinum genes differentially expressed in macrophage phagosomes using promoter fusions to green fluorescent protein. Mol Microbiol. 1998:29:1167-77.

17. Cormack BP, Valdivia RH, Falkow S. FACS-optimized mutants of the green fluorescent protein (GFP). Gene. 1996;173:33-8.

18. Valdivia RH, Hromockyi AE, Monack D, Ramakrishnan L, Falkow S. Applications for green fluorescent protein (GFP) in the host-pathogen interactions. Gene. 1996;173:47-52.

19. Ramakrishnan L, Federspiel NA, Falkow S. Granuloma specific expression of mycobacterium virulence proteins from the glycinerich PE-PGRS family. Science. 2000;288:1436-9.

Ready to submit your research? Choose BMC and benefit from:

- fast, convenient online submission

- thorough peer review by experienced researchers in your field

- rapid publication on acceptance

- support for research data, including large and complex data types

- gold Open Access which fosters wider collaboration and increased citations

- maximum visibility for your research: over 100M website views per year

At BMC, research is always in progress.

Learn more biomedcentral.com/submissions 